\title{
ASSEMBLY OF MITOCHONDRIA: SYNTHESIS AND INTRACELLULAR TRANSFER OF MITOCHONDRIAL PROTEINS
}

\author{
MATTHEW A. HARMEY*, EVA-MARIA NEHER, RICHARD ZIMMERMANN \\ and WALTER NEUPERT \\ Physiologisch-Chemisches Institut der Universität Göttingen, Humboldtallee 7, 3400 Gottingen, F.R.G.
}

(Received August 20th, 1979)

\begin{abstract}
The majority of mitochondrial proteins are synthesized on cytoplasmic ribosomes and transferred to the mitochondria where they are assembled to supramolecular structures. The intracellular transfer of these proteins appears to occur by a post-translational mechanism, i.e., it involves extramitochondrial precursor forms which are translocated in a step independent from translation. The synthesis and transfer of individual proteins was investigated in vivo, or in vitro employing homologous and heterologous cell free systems for protein synthesis. Cytochrome $c$ was initially made as the apoprotein. This precursor protein was converted to the holoprotein on uptake by mitochondria in reconstituted systems. Integrity of mitochondria was essential for the apo to holo conversion. In the case of the ADP/ATP carrier protein, an integral transmembrane protein of the inner mitochondrial membrane, the initial translation product had the same apparent molecular weight as the mature protein. It was found in soluble form in the post-ribosomal supernatant. Citrate synthase, a matrix protein, was synthesized as a precursor with an apparent molecular weight of 47000 . Transfer to the mitachondria was accompanied by cleavage to yield a molecular weight of 45000 . The significance of these results in relation to the mechanisms of intracellular transfer and of assembly of the individual proteins is discussed.
\end{abstract}

\section{Introduction}

The biogenesis of mitochondria represents a coordinated synergism between two segregated translation systems. Translation products of the nuclear coded cytoplasmic systems are transported to the organelle where they are integrated with the translation products of the organelle, to generate a functional mitochondrion. In mitochondria the imported proteins have various destinations. Some few are destined for the outer membrane, others for a location between the inner and outer membrane, others still for the inner membrane, while a further group of largely hydrophilic proteins are destined for the matrix. A close look at the structure of the mitochondrion and the nature of the proteins imported shows that some proteins may have to pass through one or two membranes while some proteins may become an integral part of

- Present address: Department of Botany, University College Dublin, Ireland. either of the two membranes. A fundamental problem in elucidating the nature of the protein transport arises in trying to decide whether there is a unified transport system for all the proteins or a variable mechanism of transport, depending, e.g., on the number of membranes a protein must traverse.

Kinetic studies with intact cells and with homologous cell free systems from Neurospora were carried out to follow the intracellular transfer of mitochondrial proteins. Applying a number of criteria it was concluded that transfer of proteins is by a post translational mechanism (Hallermayer et al., 1977; Harmey et al., 1977): (a) there is a time lag between the synthesis of proteins in the cytosol and their appearance in the mitochondria; (b) cycloheximide inhibits protein synthesis on cytoplasmic ribosomes completely but allows continued transport of proteins into the mitochondria; (c) different proteins have different kinetics of appearance in the mitochondria. These findings suggested the existence of extramitochondrial precursor pools of mitochondrial proteins. 


\section{Results}

The experiments described here were aimed at elucidating the nature of the extramitochondrial precursors, and their transport to their functional locations in the mitochondria. Three proteins from different topographical locations within the mitochondrion were studied viz. cytochrome $c$, ADP/ATP carrier protein and citrate synthase.

Cytochrome $c$ is a small protein (mol. wt 13000 ) consisting of an apoprotein and a covalently attached heme group (Heller and Smith, 1966). It is generally described as a peripheral protein of the inner membrane (De Pierre and Ernster, 1977). The apo and holo forms of cytochrome $c$ were distinguished from each other by monospecific antibodies (Korb and Neupert, 1978). A cytosolic pool of apocytochrome $c$ could be demonstrated in vivo and in vitro. In vivo pulse labelling experiments showed a correlation between the appearance and disappearance of apocytochrome $c$ in the cytosol and the appearance of labelled holocytochrome $c$ in the mitochondria. In vitro reconstitution experiments have shown that apocytochrome $c$ is first released into the postribosomal supernatant (Korb and Neupert, 1978). Import into the mitochondria is a time dependent process accompanied by attachment of heme and binding to the mitochondrial membrane (Fig. 1). The uptake and binding is dependent on the amount of mitochondria and on their integrity. Disruption of the mitochondria by agents such as Triton $\mathrm{X}-100$, treatment with deoxycholate or hypotonic media destroyed the capacity of the mitochondria to import and convert apocytochrome $c$ to the holo form. Heterologous translation systems (Pelham and Jackson, 1976; Roberts and Paterson, 1973) were programmed with messenger RNA from Neurospora and apocytochrome $c$ immunoprecipitated from the translation products. When the dissociated immunoprecipitates were subjected to SDS electrophoresis the original translation product does not have an aminoterminal extension, nor does it have a carboxyterminal extension

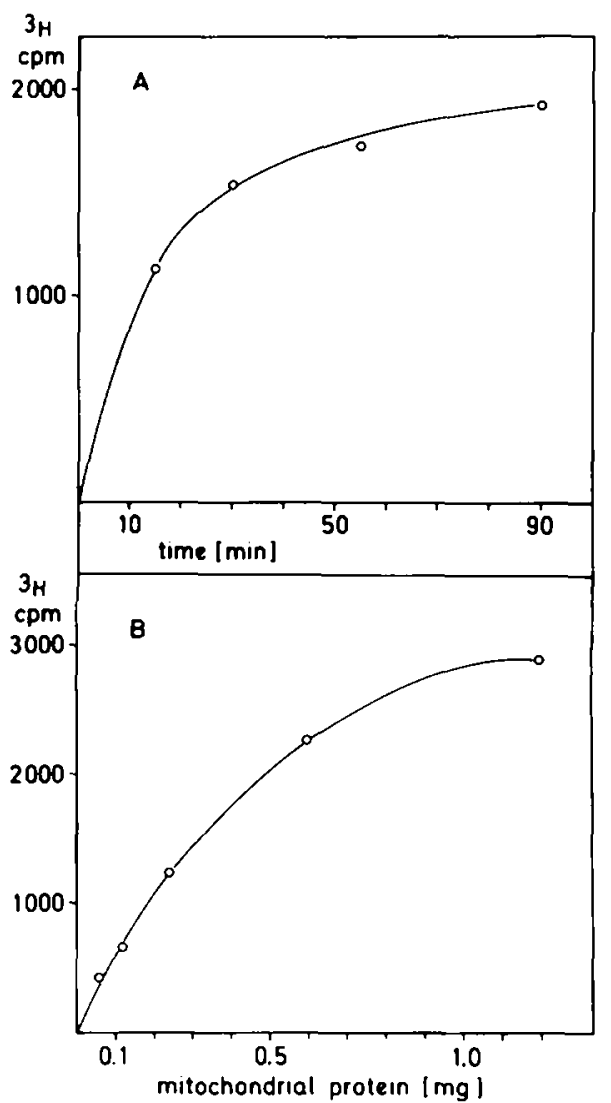

Fig. 1. Conversion of apocytochrome $c$ to holocytochrome $c$ in a reconstituted system. $\left[{ }^{3} \mathrm{H}\right]$ leucine was incorporated into a postmitochondrial fraction of Neurospora and the postribosomal supernatant prepared (Harmey et al., 1977). The supernatant was incubated with mitochondria. Following incubation, lysis of mitochondria was carried out by addition of Triton X-100 and holocytochrome $c$ was immunoprecipitated. The immunoprecipitate was subjected to SDS gel electrophoresis and the radioactivity in cytochmome $c$ determined. A: Time dependence of the formation of holocytochrome $c$. B: Dependence of the formation of holocytochrome $c$ on the amount of mitochondria in the reconstituted system ( $30 \mathrm{~min}$ incubation).

since the apparent molecular weight of the in vivo and in vitro products are identical (Fig. 2).

As an inner membrane protein we chose the ADP/ATP carrier protein, an integral membrane protein (Klingenberg, 1976). This protein has a monomeric molecular weight of 32000 and has a hydrophobic character. Kinetic experiments indicated the existence of an extramitochondrial pool (Hallermayer et 


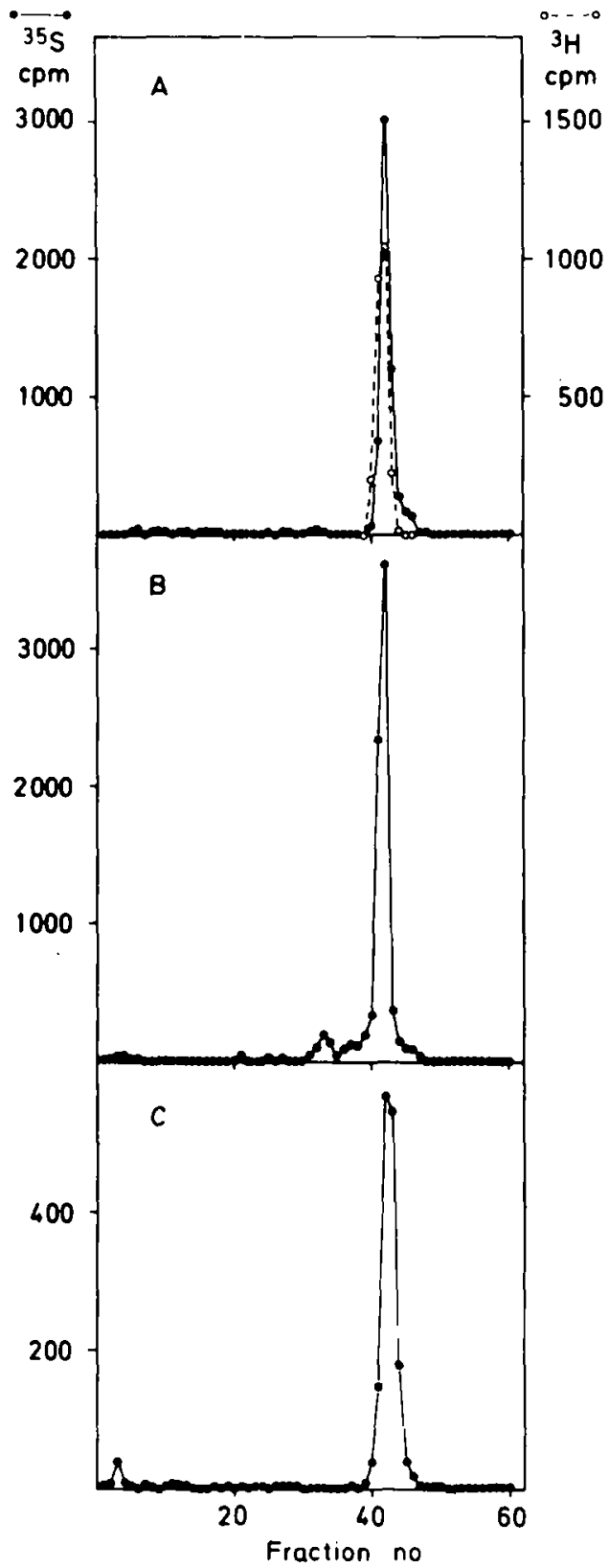

Fig. 2. Synthesis of apocytochrome $c$ in heterologous cell free systems programmed with Neurospora poly(A)-RNA. Apocytochrome $c$ was immunoprecipitated from the cell free incubation mixture with a specific antibody and protein-A-sepharase. The immunoprecipitate was subjected to SDS electrophoresis. The gel was sliced and radioactivity in gel fractions determined. A: Wheat germ system; incubation with $\left[^{35} \mathrm{~S}\right]$ methionine. Coelectrophoresis of holocytochrome $c$ labelled with $\left[{ }^{3} \mathrm{H}\right]$ leucine. B: Reticulocyte lysate; incubation with [ ${ }^{35}$ S]methionine. C: Reticulocyte lysate; incubation with $\left.{ }^{36} \mathrm{~S}\right]$ formylmethionyl-transfer-RNA. al., 1977). Synthesis in a homologous Neurospora system (Harmey et al., 1977) yielded a protein identical in apparent molecular weight to the authentic protein (Fig. 3). Also, when Neurospora total or poly(A)-RNA was translated in a rabbit reticulocyte lysate (Pelham and Jackson, 1976) or wheat germ translation system (Roberts and Paterson, 1973) the immunoprecipitable ADP/ATP carrier protein was indistinguishable from the isolated protein (Fig. 4). Furthermore when translation was carried out in the presence of ${ }^{35}$ S-labelled formylmethionyl transfer RNA (Zimmermann et al., 1979) the immunoprecipitated protein had the same molecular weight as the authentic protein (Fig. 4). The retention of the formylmethionine and the coincident molecular weight clearly indicate the absence of an aminoterminal extension. In both homologous and heterologous cell free systems and newly formed ADP/ATP carrier was detected mainly in the postribosomal supernatant.

Citrate synthase is a soluble matrix protein (Ernster and Kuylenstierna, 1970). The mature mitochondrial protein is a dimer composed of identical subunits with a

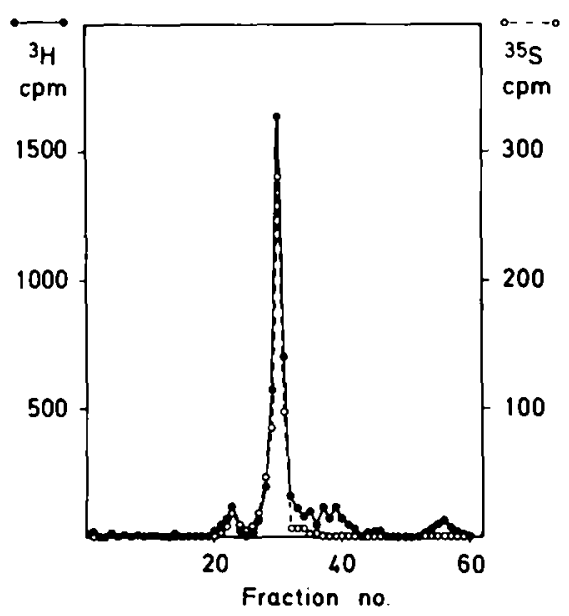

Fig. 3. Synthesis of ADP/ATP carrier in a cell free homogenate. A cell free homogenate from Neurospora cells grown in the presence of [ ${ }^{36}$ S $]$ gulfate was incubated with [ $\left.{ }^{3} \mathrm{H}\right]$ leucine for $10 \mathrm{~min}$ (Harmey et al., 1977). ADP/ATP carrier was immunoprecipitated after lysis with Triton X-100. The immunoprecipitate was analysed by SDS polyacrylamide gel electrophoresis. 


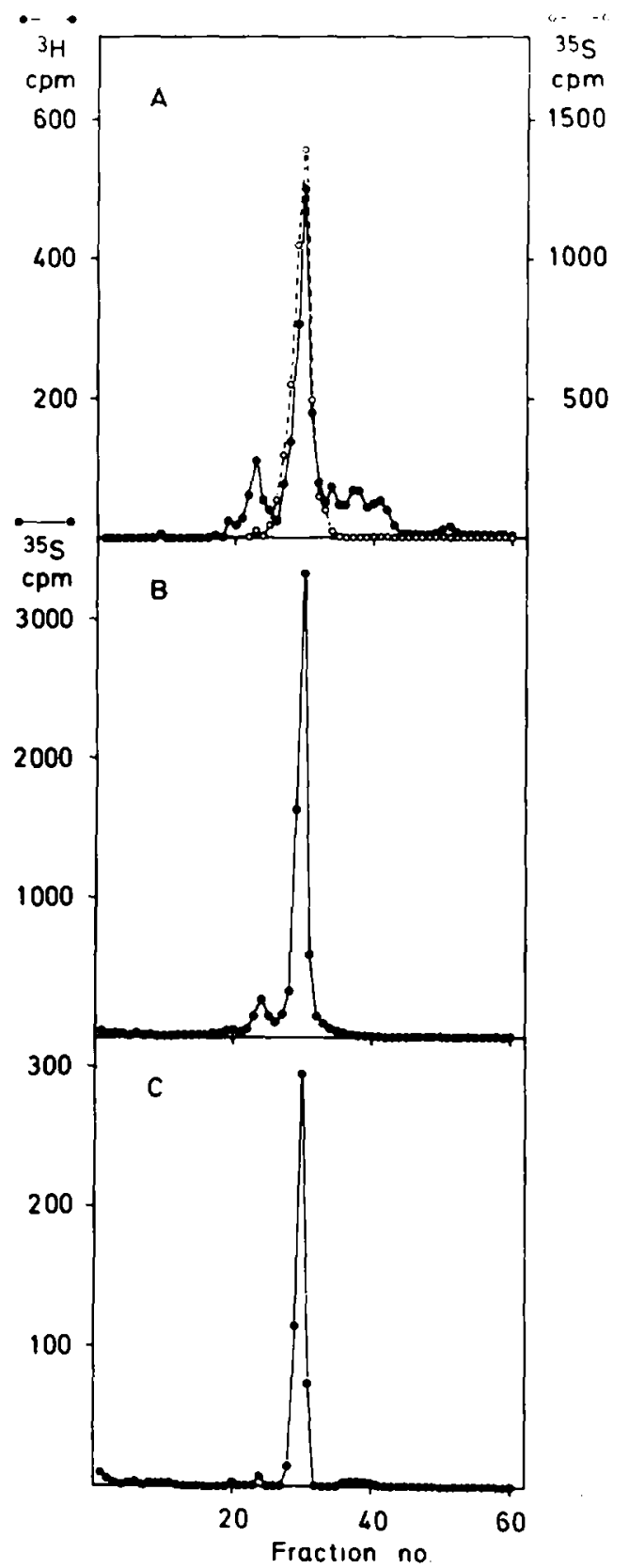

Fig. 4. Synthesis of ADP/ATP carrier in heterologous cell free systems programmed with Neurospora poly(A)-RNA. ADP/ATP carrier was immunoprecipitated from the cell free systems with a specific antibody and the immunoprecipitates were analysed by SDS-gel electrophoresis (Zimmermann et al., 1979). A: Wheat germ system; incubation with [ $\left.{ }^{3} \mathrm{H}\right]$ leucine. Coelectrophoresis of ${ }^{35} \mathrm{~S}$ labelled carrier immunoprecipitated from mitochondria. B: Reticulocyte lysate; incubation with [35] $]$ methionine. C: Reticulocyte lysate; incubation with [35]formylmethionyl-transfer-RNA. monomeric molecular weight of 45000 . In vivo pulse labelling studies at low temperature $\left(8^{\circ} \mathrm{C}\right)$ showed the appearance of a larger molecular weight monomer having a molecular weight of about 47000 , which was rapidly converted to the mature 45000 form. At room temperature the conversion was so rapid that the precursor form was undetectable. Homologous and heterologous translation systems also showed that citrate synthase was initially synthesized as a larger precursor protein (Fig. 5). The precursor protein is quite unstable compared to the authentic protein. Translation in the presence of $\left[{ }^{35}\right.$ S]formylmethionyl-RNA showed that the 47000 protein retained its initiator methionine.

\section{Discussion}

A comparison of the results obtained with the three proteins shows that only in the case of the matrix protein is there an extension of the polypeptide chain in the precursor, whereas the other two precursors are synthesized at their final length. Our results with cytochrome $c$ suggest that the apoprotein is synthesized on cytoribosomes and released into the cytosol. The uptake of apocytochrome $c$ into the mitochondria is accompanied by conversion to the holo form and requires intact mitochondria which suggests a role for the outer membrane in protein uptake.

The ADP/ATP carrier protein despite its highly hydrophobic character is synthesized on cytoribosomes and is probably released into the cytosol. The cytosolic precursor is taken up by mitochondria and integrated into the hydrophobic domain of the inner membrane. Citrate synthase on the other hand is released into the cytosol as a larger molecular weight precursor which is cleaved on or after transport to form the mature protein of the matrix. The behaviour of citrate synthase resembles that reported for the ATPase subunits of yeast mitochondria and of the cyt $b c_{1}$ complex (Maccechini et al., 1979; Coté et al., 1979).

It appears from our results and those of 


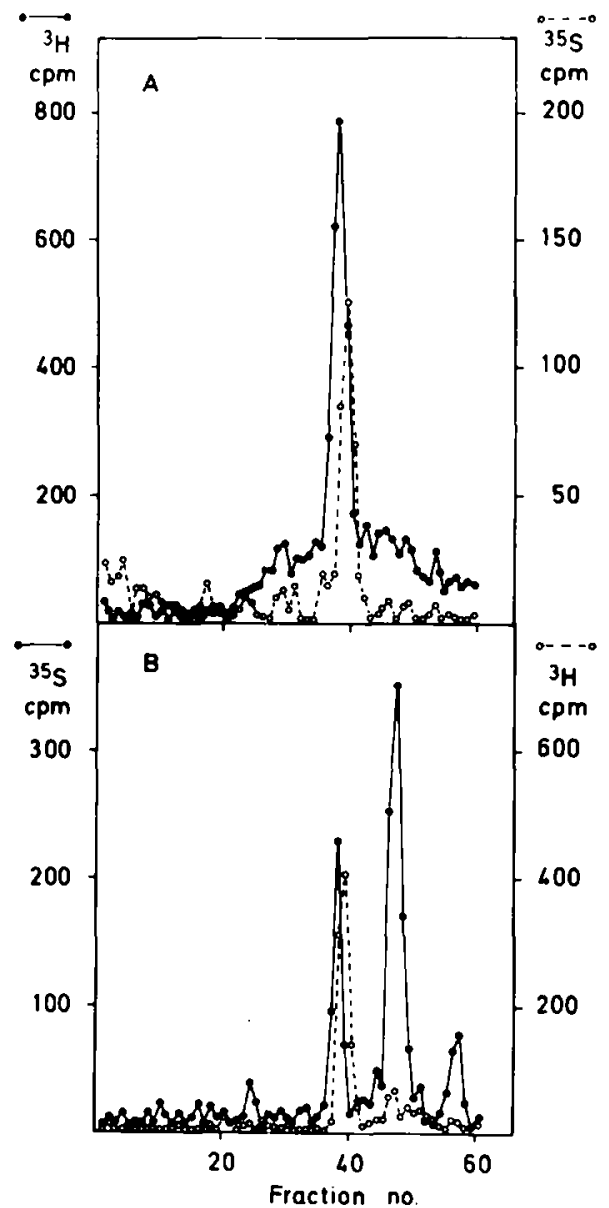

Fig. 5. Synthesis of citrate synthase in homologous and heterologous cell free systems. Immunoprecipitated citrate synthase was analysed by SDS electrophoresis. A: Neurospora cell free homogenate; $\left[{ }^{3} \mathrm{H}\right]$ leucine was incorporated into the cell free homogenate which was obtained from cells prelabelled with [ ${ }^{35}$ S $]$ methionine. B: Reticulocyte lysate programmed with Neurospora-poly(A)RNA; incubation with [ $\left.{ }^{35} \mathrm{~S}\right]$ methionine. Coelectrophoresis of ${ }^{3} \mathrm{H}$-labelled citrate synthase immunoprecipitated from mitochondria.

others (Maccechini et al., 1979; Coté et al., 1979) that signals for specific translocation may be located either in additional sequences or in the interior of the protein structure. We propose that the precursor proteins undergo changes in conformation which lead to their correct assembly. These changes may be triggered by different events, heme attachment for cytochrome $c$, membrane integration for ADP/ATP translocator, proleolytic cleavage in the case of citrate synthase. At this point in time sufficient data is not available to draw generalised conclusions regarding the role of additional or internal sequences in the transport of mitochondrial proteins. Furthermore the exact mode of transport and the role of outer and inner membranes in this transport remains to be elucidated.

\section{References}

Coté, C., M. Solioz and G. Schatz, 1979, J. Biol. Chem. 254, 1437-1439.

De Pierre, J.W. and L. Ernster, 1977, Annu. Rev. Biochem. 46, 201-262.

Ernster, L. and B. Kuylenstierna, 1970, in: E. Racker (ed.), Membranes of Mitochondria and Chloroplasts (Van-Nostrand Reinhold Co., London) p. 195.

Hallermayer, G., R. Zimmermann and W. Neupert, 1977, Eur. J. Biochem. 81, 523-532.

Harmey, M.A., G. Hallermayer, H. Korb and W. Neupert, 1977, Eur. J. Biochem. 81, 533-544.

Heller, J. and E.L. Smith, 1966, J. Biol. Chem. 31653180.

Klingenberg, M., 1976, in: Martonosi, A.N. (ed.), Vol. 3, The Enzymes of Biological Membranes: Membrane Transport (Plenum Publ. Co., New York) pp. 383-438.

Korb, H. and W. Neupert, 1978, Eur. J. Biochem. 91, $609-620$.

Macoechini, M.L., Y. Rudin, G. Blobel and G. Schatz, 1979, Proc. Natl. Acad. Sci. USA 76, 343-347.

Pelham, H.R.B. and R.J. Jackson, 1976, Eur. J. Biochem. 67, 247-256.

Roberts, B.E. and B.M. Paterson, 1973, Proc. Natl. Acad. Sci. USA 70, 2330-2334.

Zimmermann, R., N. Palnch, M. Sprinzl and W. Neupert, 1979, Eur. J. Biochem. 99, 247-252. 